\title{
Greenhouse gas-related predictability of regional climate model trends in the Mediterranean area
}

\author{
A. Paxian, ${ }^{\mathrm{a}, *}$ E. Hertig, ${ }^{\mathrm{b}}$ G. Vogt, ${ }^{\mathrm{a}}$ S. Seubert, ${ }^{\mathrm{b}}$ J. Jacobeit ${ }^{\mathrm{b}}$ and H. Paeth ${ }^{\mathrm{a}}$ \\ ${ }^{a}$ Institute of Geography and Geology, University of Würzburg, Germany \\ ${ }^{\mathrm{b}}$ Institute of Geography, University of Augsburg, Germany
}

\begin{abstract}
This study investigates whether a regional climate model (RCM) driven by a global general circulation model (GCM) in a nesting approach with observed atmospheric $\mathrm{CO}_{2}$ concentrations shows predictability for temperature and precipitation trends during 1961-1990 in the Mediterranean area, a region strongly influenced by large-scale circulation. Resulting discrepancies between model and observations raise the question whether the model predictability increases after removing impacts of mid-latitude circulation variability. For temperature and precipitation trends we use the RCM REMO and the observational dataset E-OBS, and for atmospheric circulation the driving coupled GCM ECHAM5/MPI-OM and NCEP/NCAR reanalyses. Cross-validated multiple regression analyses between large-scale circulation and regional temperature and precipitation are performed for observed and simulated data. The impact of circulation is removed from the original temperature and precipitation data, and the trends of circulation-related and circulation-unrelated parts are compared. The circulation-related trends of models and observations show discrepancies owing to differing observed and simulated mid-latitude circulation dynamics, i.e. different temporal evolutions of North Atlantic Oscillation and East Atlantic pattern in winter and East Atlantic Jet and a blocking pattern in summer. Such differences can be related to unknown initial conditions of GCM simulations. In fact, we find strong impacts of initial conditions on mid-latitude circulation dynamics of ECHAM5/MPI-OM ensemble members over 30-year periods. The agreement between simulated and observed circulation-unrelated trends is generally higher than for original trends indicating that the predictability of this nesting approach increases by removing impacts of mid-latitude circulation variability. We conclude that initial conditions affect climate variability up to the multi-decadal timescale, at least in parts of the globe which are governed by extratropical circulation modes, and hence, hinder the comparability of simulated and observed climate trends over time periods shorter than the timescale dominated by radiative forcing. In the Mediterranean Basin the latter is definitely beyond 30 years.
\end{abstract}

KEY WORDS regional climate modelling; mid-latitude circulation; Mediterranean climate; model validation; model predictability

\section{Introduction}

Dynamical climate models are applied to understand the physical processes determining climate and to project future climate change under increasing greenhouse gas (GHG) concentrations. Recent climate model simulations of the Fourth Assessment Report (AR4) of the Intergovernmental Panel on Climate Change (IPCC) predict strong global warming trends and increased spatial rainfall variability under enhanced radiative forcing in the 21st century (Christensen etal., 2007). However, this long-term climatic response to GHG emissions projected by climate models is overlaid or even masked by interdecadal model variability which arises from factors like tropical climate dynamics, mid-latitude circulation, ocean-atmosphere interactions, soil moisture variability or glacier dynamics, and thus remains unpredictable for

\footnotetext{
* Correspondence to: A. Paxian, Institute of Geography and Geology, University of Wurzburg, Am Hubland, 97074 Wurzburg, Germany. E-mail: andreas.paxian@uni-wuerzburg.de
}

climate models. To enhance confidence in future model projections of temperature and precipitation it is essential to examine if climate models are able to reproduce not only observed climatic means but also present-day climatic trends.

Regional climate models (RCMs) are able to capture present-day temperature and precipitation means and trends if forced by observed boundary conditions but hardly reproduce observed trends if driven by general circulation model (GCM) simulations. For example, simulations of the RCM REMO (Jacob etal., 2001, 2007) forced by ECMWF ERA15 reanalyses and analyses during 1979-2003 (Gibson etal., 1997) reproduce the main features of observed means, trends and large-scale circulation in tropical West Africa (Paeth etal., 2005) and the Mediterranean region (Paeth and Hense, 2005). However, if driven by the coupled atmosphere-ocean GCM ECHAM5/MPI-OM (Roeckner etal., 2003) REMO does not capture the observed interdecadal Sahel drought during 1960-2000 because of lacking atmosphere-vegetation feedbacks and different 
oceanic boundary conditions in the GCM (Paeth etal., 2009). Thus, differing observed and simulated trends do not necessarily indicate poor model performance but can be related to higher-frequency variations which are below the predictive timescale from a given forcing and overlay background climate change trends.

Driving GCMs strongly impact RCMs in such nesting approaches, e.g. control the large-scale circulation (Giorgi etal., 2004). Giorgi and Lionello (2008) and Déqué etal. (2005) find larger uncertainty for the usage of different GCMs than for RCMs over Europe, especially in winter, indicating the strong impact of GCM boundary conditions on the RCM large-scale circulation. However, Osborn (2004) states that climate models are still not able to reproduce the interannual variability and multidecadal trends of observed large-scale atmospheric modes, e.g. the North Atlantic Oscillation (NAO). Giorgi and Lionello (2008) report that AR4 GCM simulations agree with Mediterranean temperature and precipitation means from gridded CRU station data (Climatic Research Unit, New etal., 2000). However, they do not reproduce the large observed winter drying trend related to the strong NAO increase in the 1980s and 1990s because this observed natural variability event is not captured in the GCMs. Thus, the question arises whether climate models better reproduce observed climate trends if disturbing shorter-term effects, e.g. from mid-latitude circulation dynamics, are removed from the data sets.

In this study, we evaluate the predictability of such a nesting approach and its skill to reproduce observed temperature and precipitation trends in the Mediterranean area. This domain is chosen for several reasons: First, the Mediterranean region has been identified as a climate change hot spot, i.e. one of the most responsive regions to future changes in mean and variability of temperature and precipitation (Wang, 2005; Giorgi, 2006), revealing strong future warming and drying trends projected by the IPCC AR4 climate model simulations (Christensen et al ., 2007). In such hot spot regions one might expect strong model predictability based on observed $\mathrm{CO}_{2}$ concentrations. Furthermore, the Mediterranean area is strongly influenced by the interdecadal variability of mid-latitude circulation dynamics owing to its position downstream of the centres of North Atlantic cyclogenesis which show strongly differing single model simulations because of high influence of initial conditions (Paeth and Hense, 2002; Rauthe etal., 2004). The impact of large-scale circulation is strongest in the western Mediterranean in winter when mid-latitude cyclone variability is greatest (Trigo etal., 2006). The major mid-latitude mode of atmospheric variation (teleconnection) is the NAO which strongly increased in the winters of 1980s and 1990s (Hurrell, 1995) inducing Atlantic and Mediterranean storm track variations (Trigo etal., 2000) and strong decreases of Mediterranean precipitation (Quadrelli et al., 2001; Xoplaki et al., 2004; Jacobeit et al., 2007). Further mid-latitude modes of variation impacting on Mediterranean temperature and precipitation during different seasons are the East Atlantic (EA) pattern (Sáenz etal.,
2001), the East Atlantic/West Russia (EA/WR) pattern (Xoplaki, 2002; Krichak and Alpert, 2005), the Scandinavian (SCAND) pattern (Quadrelli et al ., 2001; Xoplaki, 2002), the East Atlantic Jet pattern (EA-Jet) and the Mediterranean Oscillation, a regional manifestation of the NAO (Conte etal., 1989; Dünkeloh and Jacobeit, 2003). Owing to the strong impacts of mid-latitude circulation and high heterogeneity of orography and land-sea contrasts climate simulations in the Mediterranean area are very challenging, making the use of a high-resolution RCM indispensable. Finally, the Mediterranean region provides several high-quality, high-resolution and longterm model and observational datasets, e.g. simulations of the RCM REMO (Jacob etal., 2001; Jacob et al., 2007) and the gridded observational dataset of E-OBS (Haylock etal., 2008), making this study on model predictability for present-day climate trends possible.

In this study, we analyse if an RCM driven by a GCM and the observed atmospheric $\mathrm{CO}_{2}$ concentrations (as only real boundary condition) shows predictability for temperature and precipitation trends in the Mediterranean area. The time period under consideration is the climate normal period 1961-1990. Resulting discrepancies between model and observations (see Results section) raise the question if the model predictability increases after removing the impact of mid-latitude circulation variability on temperature and precipitation time series. We use the RCM REMO forced by the coupled atmosphere-ocean GCM ECHAM5/MPI-OM and the gridded E-OBS dataset for simulated and observed temperature and precipitation. For simulated and observed circulation we consider data of the driving GCM and global NCEP/NCAR reanalyses. For both model and observational data a statistical model is set up using crossvalidated multiple regression analyses between largescale modes of variation and regional temperature and precipitation. The impact of circulation on temperature and precipitation is estimated and removed from the original time series. Subsequently, trends of the resulting circulation-unrelated temperature and precipitation time series are compared between simulations and observations. The following section describes the model and observational data considered in this study and depicts the applied methods of trend and EOF (empirical orthogonal function) analysis and the statistical model of crossvalidated multiple regression. The results of original trend validation, multiple regression analysis and analysis of circulation-unrelated trends are presented in Section 3. Finally, Section 4 gives a short summary and a discussion of the results.

\section{Data and methods}

Observed temperature and precipitation are taken from the land-only daily high-resolution E-OBS Version 2.0 dataset (Haylock etal., 2008) of the EU-FP6 project ENSEMBLES. This gridded dataset has been interpolated from daily station time series of the European Climate 

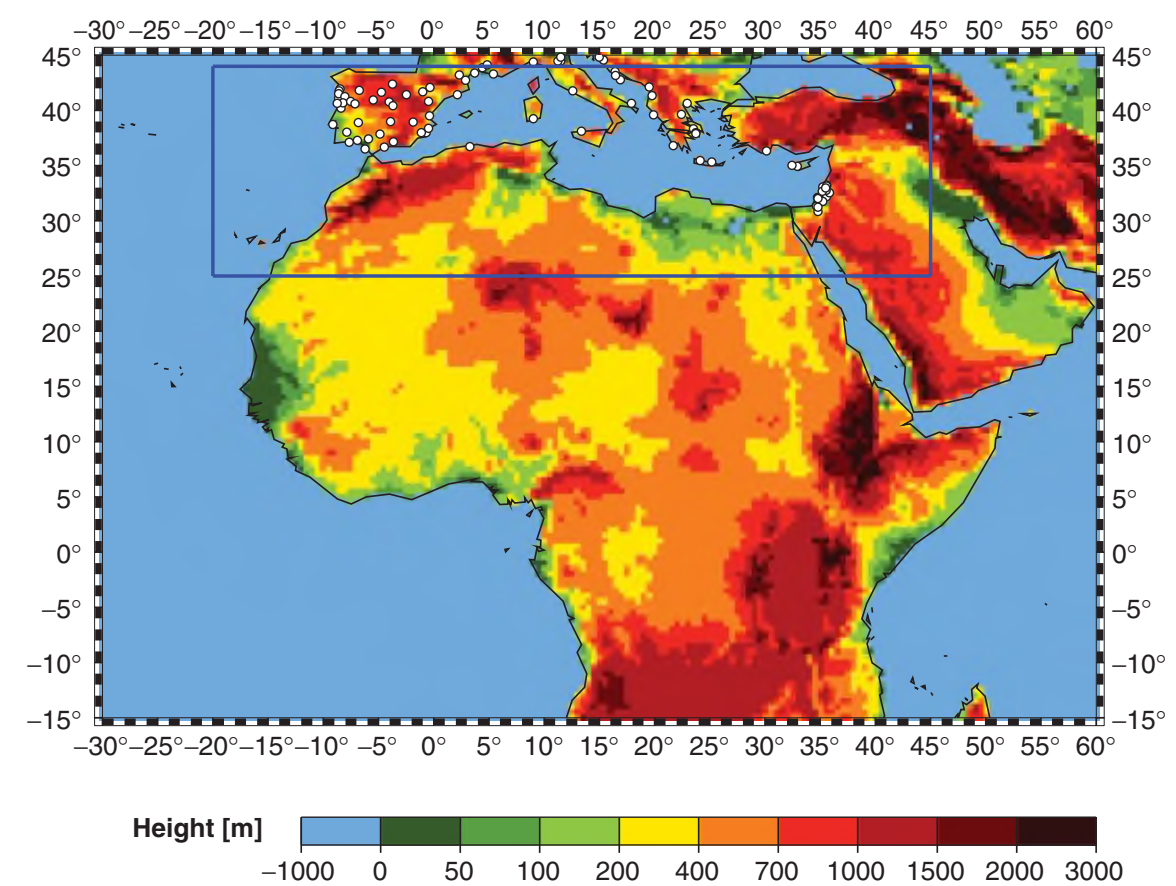

Figure 1. Full model domain and height above sea level [m] of the regional climate model REMO on $0.5^{\circ}$ resolution, the Mediterranean area of investigation (blue frame) and the applied daily Mediterranean temperature and/or precipitation stations (circles).

Assessment \& Dataset project (ECA\&D). It covers whole Europe and parts of northern Africa from 21 to $75^{\circ} \mathrm{N}$ and from $49^{\circ} \mathrm{W}$ to $68^{\circ} \mathrm{E}$ on a regular $0.5^{\circ}$ grid for the time period 1950-2008. Besides best estimate values daily standard errors are available for each grid box, describing interpolation uncertainty especially in areas with low station density. However, owing to time lacks we only consider those E-OBS grid boxes which fulfil the following standards for completeness of observational time series slightly modified from Moberg and Jones (2005): A complete month contains 2 missing days maximally, a complete season contains no missing months, and a complete time series no missing seasons in the time period 1961-1990. Following these rules several E-OBS grid boxes in northern Africa, Near East and Turkey are omitted in different seasons.

For temperature and precipitation trend analysis additional daily station data for the Mediterranean area have been collected from the GLOWA Jordan River Project (Global Change and the Hydrological Cycle, Kunstmann etal., 2006), from the EMULATE project (European and North Atlantic daily to MULtidecadal climATE variability, Moberg etal., 2006), from the ECA\&D (Klein Tank etal., 2002), and, in particular, by MedCLIVAR cooperation resulting in 189 temperature and 299 precipitation station records. However, only 69 stations for mean temperature and 79/64 stations for winter/summer precipitation can be retained for subsequent analyses (Figure 1) after testing homogeneity following Wijngaard etal. (2003) and applying the data completeness test mentioned before.

Simulated temperature and precipitation are taken from the hydrostatic RCM REMO. It has been developed at the Max-Planck Institute for Meteorology (MPIM) and designed for applications at the synoptic scale (Jacob etal., 2001, 2007) deriving physical parameterizations from the GCM ECHAM4 (Roeckner etal., 1996). In the version used here the model domain is centred over Africa and extends from $30^{\circ} \mathrm{W}$ to $60^{\circ} \mathrm{E}$ and from $15^{\circ} \mathrm{S}$ to $45^{\circ} \mathrm{N}$ with a horizontal resolution of $0.5^{\circ}$ and 20 hybrid vertical levels up to $25 \mathrm{~km}$ height (Figure 1, Paeth etal., 2009). In this study we analyse the Mediterranean sector from $20^{\circ} \mathrm{W}$ to $45^{\circ} \mathrm{E}$ and 25 to $44^{\circ} \mathrm{N}$. Two grid point rows $\left(1^{\circ}\right)$ have been removed from the northern rim to avoid lateral boundary effects. The REMO simulations are nested into simulations of the coupled GCM ECHAM5/MPI-OM (Roeckner et al., 2003) for the time period 1960-2050. During 1961-2000 observed GHG emissions and sulphate aerosol conditions are applied. For 2001-2050, the IPCC Special Report on Emission Scenarios (SRES, Nakicenovic and Swart, 2000) A1b and B1 emission scenarios and corresponding land cover change scenarios following a stochastic land cover change model (Paeth et al., 2009) are considered. For each scenario and the 20th-century simulation three ensemble members following different initial conditions have been performed to capture the corresponding uncertainty. Trend analyses in this study are based on the respective ensemble means.

For the investigation of observed mid-latitude circulation variability we take monthly sea level pressure data at $2.5^{\circ}$ resolution from the global reanalyses of the National Centers for Environmental Prediction/National Center for Atmospheric Research (NCEP/NCAR, Kalnay etal., 1996) for the time period 1948-2008. We apply reanalysis data to analyse observed large-scale circulation 
because we aim at including the influence of the whole North Atlantic circulation dynamics on the Mediterranean area which extends beyond the European E-OBS grid.

To derive simulated mid-latitude circulation we use sea level pressure data from the coupled GCM ECHAM5/MPI-OM (Roeckner etal., 2003) which drives the considered REMO simulations. As for observations we include the entire influence of North Atlantic circulation dynamics which extends beyond the REMO model domain centred over Africa. The ECHAM5/MPI-OM simulations cover the time period 1860-2100 and feature a horizontal resolution of T63 $\left(1.875^{\circ}\right)$. The forcing is consistent with REMO applying observed GHG emissions for 1860-2000 and SRES A1b und B1 emission scenarios from 2001 onward. We analyse the ensemble mean values of the three ECHAM5 ensemble members corresponding to the considered REMO members.

From E-OBS and REMO temperature and precipitation data and corresponding station records we calculate seasonal means of winter (DJF), spring (MAM), summer (JJA) and autumn (SON) during 1961-1990. Simulated and observed seasonal trends are calculated using linear regression, and the corresponding regression coefficients are tested two-tailed at a significance level of $5 \%$. Prerequisites of linear regression, i.e. normal distribution of original data and residuals as well as absence of autocorrelation, are successfully proved as well. Only some small regions in north-eastern Africa, Near and Middle East, do not show normal distribution of summer rainfall data. However, most of these regions have already been omitted due to missing data completeness (see above).

We apply s-mode EOF analysis (von Storch and Zwiers, 1999; Wilks, 2006) to seasonally averaged NCEP/NCAR and ECHAM5/MPI-OM sea level pressure anomalies of 1961-1990 and use the leading ten EOFs to represent the most important observed and simulated modes of variation of mid-latitude circulation dynamics. These leading ten EOFs explain over $90 \%$ of the total variance of observed and simulated sea level pressures in every season and are thus considered to cover all essential patterns of circulation variability necessary for the scope of this study. For better comparison, the ECHAM5/MPI-OM data is interpolated to the $2.5^{\circ}$ resolution of the NCEP/NCAR reanalyses by quadratic spline interpolation. The geographical area considered for midlatitude circulation extends from $70^{\circ} \mathrm{W}$ to $50^{\circ} \mathrm{E}$ and from 20 to $70^{\circ} \mathrm{N}$ in order to include the influence of North Atlantic circulation dynamics which is very important for the Mediterranean area. In addition, the sea level pressure data is weighted by the square root of the cosine of latitude. Finally, the resulting maps of eigenvector elements (loadings) and the principal component (PC) time series are multiplied by -1 if necessary to fit the convention on modes of variation from the literature (Barnston and Livezey, 1987; NOAA-CPC, 2010). We apply an unrotated EOF analysis because the resulting winter NAO pattern agrees much better with the spatial pattern and temporal evolution of the winter NAO known from the literature mentioned above which is essential for this study on Mediterranean climate.

To estimate the impact of initial conditions on midlatitude circulation dynamics a one-way analysis of variance (von Storch and Zwiers, 1999; Paeth and Hense, 2002) is performed for the circulation variability of the three ECHAM5/MPI-OM ensemble members. The single simulation data of 1961-2050 is projected onto all seasonal modes of variation of the ECHAM5/MPIOM ensemble mean for 1961-1990 determined above. This results in equal patterns but different PC time series. The one-way analysis of variance separates the total variance of a model ensemble exposed to identical external forcing into internal and external variability. The data $X_{j k}$ of $k=1, \ldots, m$ ensemble members at $j=1$, $\ldots, n$ time steps can be described by a linear model containing the total mean $\mu$, the external treatment effect $\beta_{\mathrm{j}}$ (denoting a common signal in all members) and the residual component $\epsilon_{j k}$ (due to differing initial conditions of different members):

$$
X_{j k}=\mu+\beta_{j}+\epsilon_{j k}
$$

The total variance explained by the external treatment effect is calculated by using the sum of squares of treatment effect and residual variance, and tested for significance via the $F$-test comparing both components (von Storch and Zwiers, 1999). The one-way analysis of variance is performed here to estimate the fractions of internal and external variability within the ECHAM5/MPI-OM model ensemble for each EOF in each season of the time period 1961-1990 separately.

A statistical model is used to determine the kind and strength of the impact of seasonal NCEP/NCAR and ECHAM5/MPI-OM mid-latitude circulation variability on seasonal Mediterranean E-OBS and REMO temperature or precipitation trends, respectively. We apply a modified version of a cross-validated stepwise linear multiple regression model developed by Paeth and Hense (2003) following von Storch and Zwiers (1999). This model has been further improved and evaluated for several low latitude regions by Paeth etal. (2006). We aim at finding relationships between the predictand time series of seasonal temperature or precipitation and the predictor time series of leading mid-latitude modes of variation for each grid box in the Mediterranean region. In order to evaluate the robustness of the relationships found between predictand and predictors and to avoid overfitting of the statistical model the multiple regression is tested by cross validation. This test is performed in each of 1000 iterations using six random bootstrap years from the standardized predictand and predictor time series of the time period 1961-1990. For precipitation only those grid boxes are considered which have more values greater than zero than the number of bootstrap years in order to guarantee that after removal of all bootstrap years the resulting dataset contains at least one value greater than zero. This condition omits some E-OBS grid boxes in 
Egypt and Near East in summer. After performance of all 1000 iterations, we carry out a final stepwise multiple regression analysis for the time period 1961-1990 without bootstrap years considering only those predictors that have been identified by cross-validation to be robust in at least $50 \%$ of all iterations. This robustness threshold only allows the most robust seasonal modes of variation to be correlated to the seasonal temperature or precipitation time series. The final stepwise linear multiple regression analysis reveals the following information at each grid box: the number and sequence of selected predictors, the corresponding regression coefficients and robustness values (as share of 1000 iterations) and the percentage of total temperature or precipitation variance that can be explained by each predictor and by the total of all predictors selected after 1000 iterations of crossvalidation.

After having determined the relationships between seasonal temperature or precipitation and seasonal mid-latitude modes of variation, original REMO and E-OBS temperature and precipitation time series during 1961-1990 are split into circulation-related and circulation-unrelated parts. The anomaly time series of the circulation-related part $\widehat{y}_{j}$ at $j=1, \ldots, n$ time steps is derived by summing up the PC anomaly time series of all predictors $x_{i j}$ selected in cross-validated linear multiple regression multiplied by the corresponding regression coefficients $a_{i}$ for $i=1, \ldots, m$ regression steps and adding the multiple regression intercept $a_{0}$. To transform this anomaly time series of the circulation-related part back to the original data, it is further multiplied by the standard deviation $s$ of the original temperature or precipitation time series and the corresponding long-term mean $m$ is added:

$$
\widehat{y_{j}}=\left(a_{0}+\sum_{i=1}^{m} a_{i} x_{i j}\right) \cdot s+m
$$
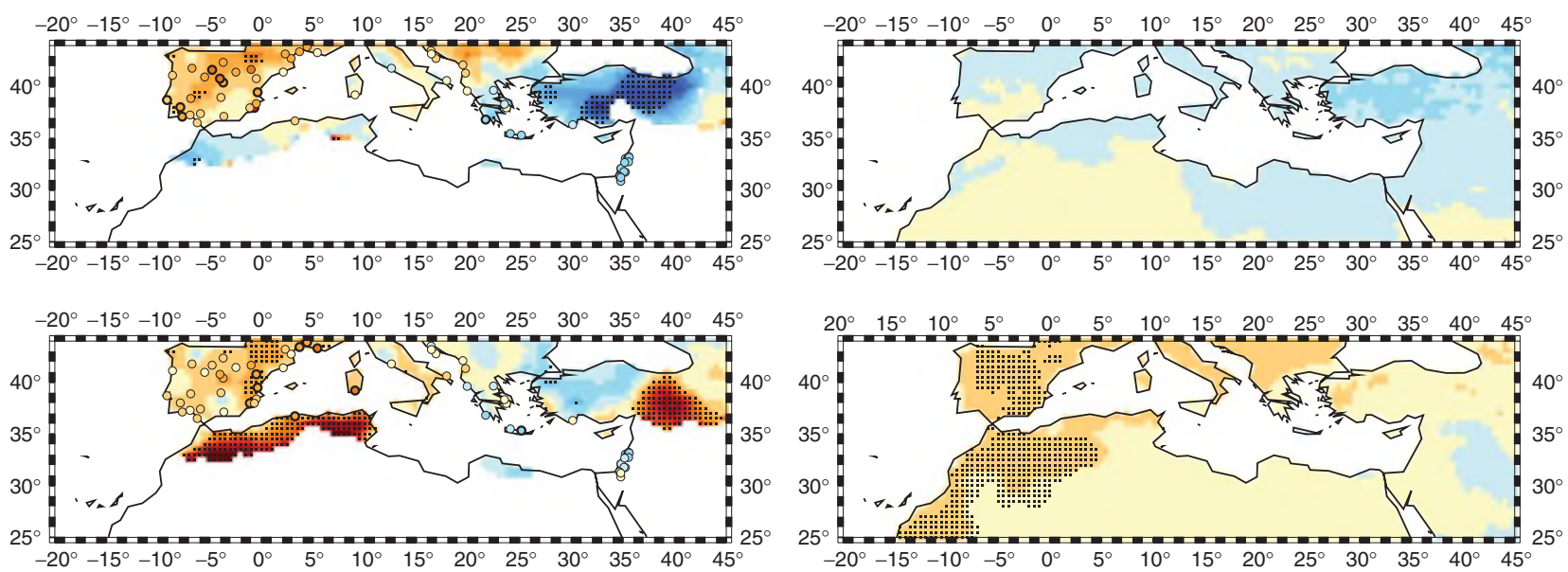

$\mathrm{T}\left[{ }^{\circ} \mathrm{C} / 30\right.$ years $]$

The time series of the circulation-unrelated part $\dot{y}_{j}$ results from subtracting the circulation-related part $\hat{y}_{j}$ from the original temperature or precipitation time series $y_{j}$ at each time step $j$. Finally, the seasonal trends of the time series of both circulation-related and circulationunrelated parts are calculated and the same two-tailed test is applied as for the original time series.

\section{Results}

In general, the validation of REMO temperature and precipitation means during 1961-1990 shows good agreements in seasonal and spatial distributions over the Mediterranean region in comparison to E-OBS observations (not shown, $c f$ Paeth and Hense, 2005). The focus of this study is on the validation of present-day REMO temperature and precipitation trends with both station and E-OBS data. However, for multiple regression analysis only the E-OBS data is used.

\subsection{Validation of original seasonal trends}

The first question is whether REMO, nested in a freerunning simulation by ECHAM5/MPI-OM (forced by observed $\mathrm{CO}_{2}$ concentrations), shows any predictability for Mediterranean temperature and precipitation trends during 1961-1990.

At first seasonal REMO temperature trends during 1961-1990 are validated with E-OBS and station data (Figure 2). Generally, a very good agreement exists between station and gridded observational data (spatial correlation coefficients $0.86 / 0.77$ for winter/summer). Station data show high density over the Iberian and Balkan peninsulas and the Near East but there are hardly any data over Turkey and the Atlas Mountains. In winter, a very strong and significant E-OBS cooling pattern is obvious over Turkey reaching values of up to $-4{ }^{\circ} \mathrm{C}$ (Figure 2, upper left). Adequate station records are

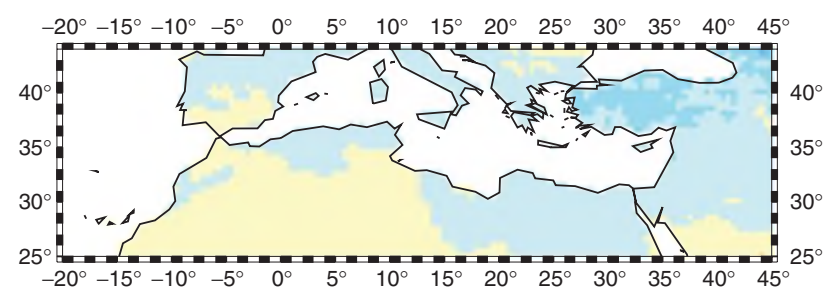

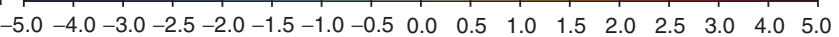

Figure 2. Validation of winter (above) and summer (below) temperature trends during 1961-1990 of the regional climate model REMO (right) with the observational dataset E-OBS (left) and original station data (left, circles) applying a significance level of 5\% (dots, bold circles). 
prominent in the Near East. Significant warming has been observed in parts of Spain. REMO reproduces a slight cooling pattern over Turkey with values of up to $-1{ }^{\circ} \mathrm{C}$ not reaching significance and shows negligible trends over the western Mediterranean (Figure 2, upper right). Concerning summer, we can state strong and significant warming trends over Spain, the Atlas Mountains and eastern Turkey and a few significant cooling trends over western Turkey in E-OBS (Figure 2, lower left). Station records show similar warming patterns over Spain. The corresponding REMO trends capture the warming over Spain and to a lower extent that over the Atlas Mountains but there are no significant trends prevailing over Turkey (Figure 2, lower right). Analysing the different REMO ensemble members to estimate the impact of initial conditions we can state that the observed summer warming over the western Mediterranean and to a lower extent the winter cooling over Turkey are captured by two members in each case. In contrast to that, one member even describes winter warming patterns over Turkey (not shown).

Concerning the validation of seasonal REMO precipitation trends with E-OBS and station data, strong differences can be found in winter (Figure 3). Precipitation station records agree well with gridded observational data (spatial correlation coefficients $0.48 / 0.78$ for winter/summer) and show a similar distribution of station density to that of temperature described above. Observations show strong and significant drying patterns of up to $-300 \mathrm{~mm}$ over the whole northern Mediterranean region but trends of opposite signs in E-OBS and station data over the Near East (Figure 3, upper left). REMO reproduces these drying patterns but with less intensity reaching a maximum of $-200 \mathrm{~mm}$ in Portugal and nearly no significance (Figure 3, upper right). Summer hardly shows any strong precipitation trends. Some small drying tendencies over the Balkans and the Atlas Mountains in both model and observations are prominent (Figure 3, lower left and right). The analysis of ensemble member trends reveals two members with slightly lower winter drying over southern Europe and Turkey than observed, and in contrast to that, one member with adequately strong wetting patterns (not shown).

Thus, this nesting approach is not able to capture all observed patterns, especially in winter, leading to the conclusion that the only real boundary condition $\mathrm{CO}_{2}$ does not clearly prevail over other drivers influencing Mediterranean temperature and precipitation, e.g. mid-latitude circulation, tropical climate dynamics or ocean-atmosphere interactions. High impact of initial conditions on seasonal trends of REMO ensemble members can be identified. Hence, these results confirm former findings that temperature and precipitation predictability in certain regions can be strongly limited by inherent natural climate variability, e.g. over North America (Deser etal., 2012).

\subsection{Validation of seasonal mid-latitude circulation variability}

The impacts of other drivers on Mediterranean temperature and precipitation variability have to be considered in order to understand and evaluate the differences between simulated and observed trends during 1961-1990. Like many former studies have shown (see Introduction section) one of the main drivers in the Mediterranean area is the mid-latitude circulation variability, especially in winter.

Therefore, we validate the simulated seasonal midlatitude circulation variability with observations, i.e. the leading EOFs of ECHAM5/MPI-OM and NCEP/NCAR seasonal sea level pressure during the 1961-1990 winter and summer seasons are compared with each other. Figure 4 shows the loadings (left) from NCEP/NCAR and the PC time series (right) from both NCEP/NCAR and ECHAM5/MPI-OM of those EOFs which are identified by the statistical model as the most influential modes of variation for Mediterranean temperature and precipitation (see below). Corresponding simulated loadings are not shown because they are basically consistent with observations. In general, ECHAM5/MPI-OM is characterized
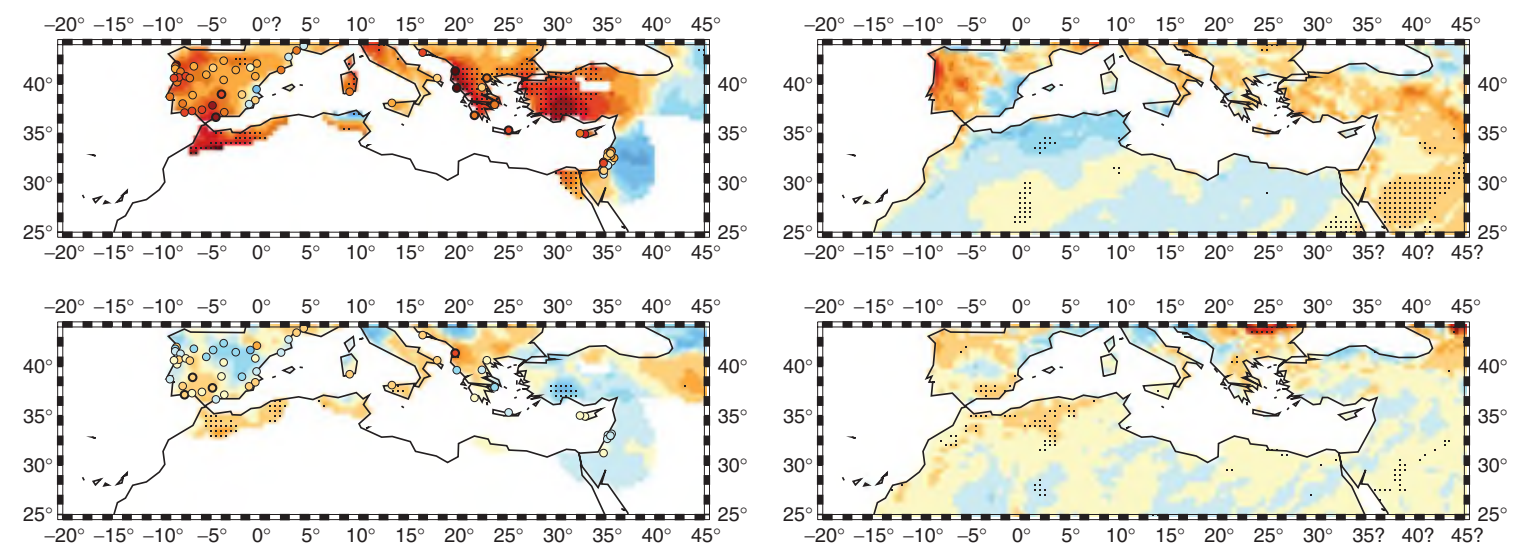

$P[\mathrm{~mm} / 30$ years $]$

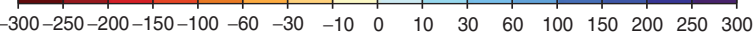

Figure 3. Same as Figure 2 but for winter and summer precipitation. 


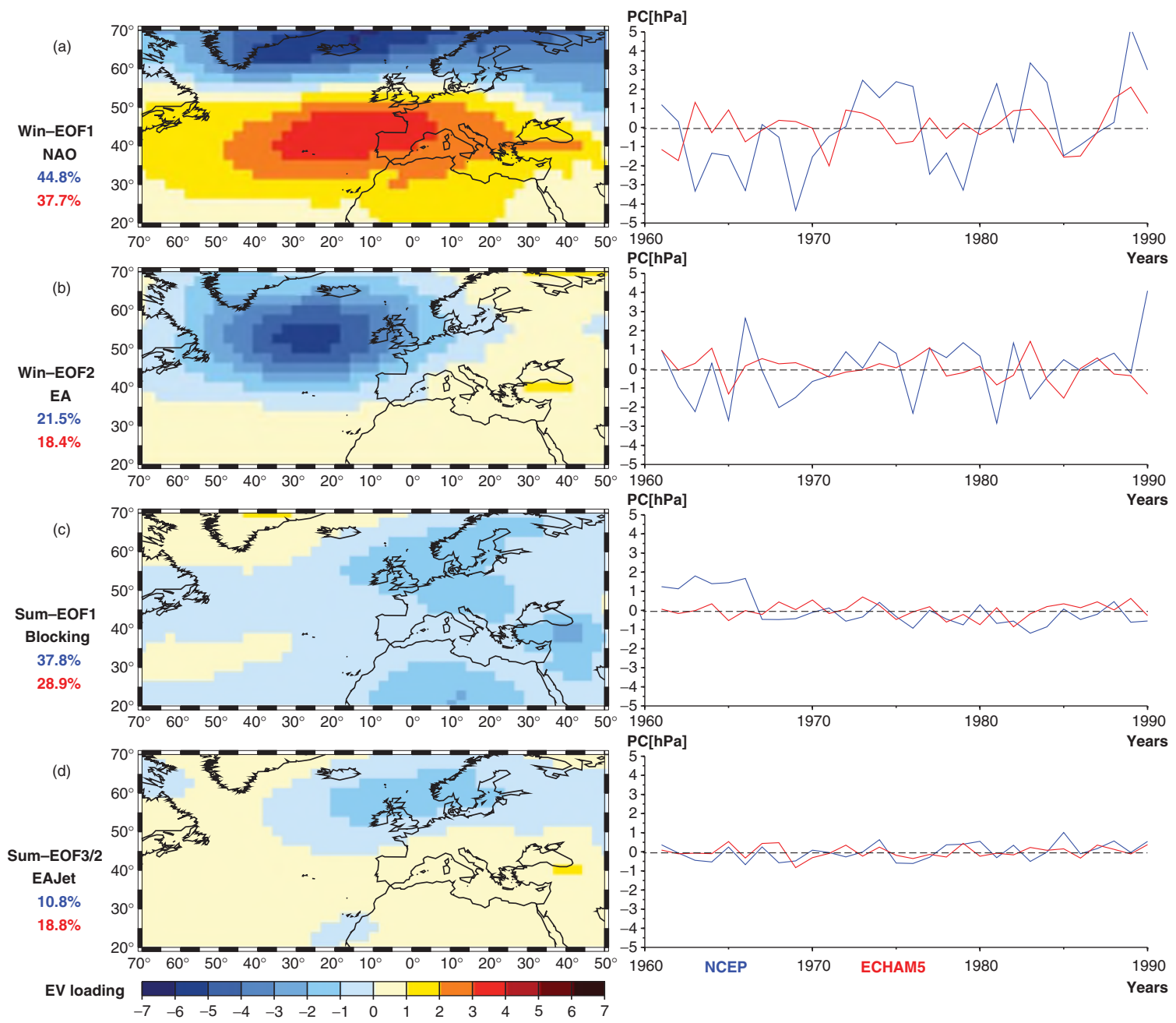

Figure 4. Mid-latitude large-scale modes of variation during 1961-1990: Eigenvector loadings derived from the NCEP/NCAR reanalysis dataset with explained variances [\%] for NCEP/NCAR (blue) and the coupled GCM ECHAM5/MPI-OM (red) (left) and PC time series of NCEP/NCAR (blue) and ECHAM5/MPI-OM (red) (right) of those EOFs with highest impact (mostly first and second EOFs) on Mediterranean temperature and precipitation in winter and summer. Sum-EOF3/2 signifies the third EOF of NCEP/NCAR and the second EOF of ECHAM5/MPI-OM in summer (see text for further explanation).

by leading EOFs with lower variability than those from NCEP/NCAR because the ensemble mean of three runs is analysed. However, EOFs of single runs show similar variability to observations (see below).

Both simulated and observed winter modes of variation show high variability and are consistent with the major large-scale modes of Northern Hemisphere atmospheric circulation impacting on the Mediterranean climate from the literature (Barnston and Livezey, 1987; Trigo et al ., 2006; NOAA-CPC, 2010): The winter EOFs of NCEP/NCAR describe a strengthening NAO in the first EOF (Figure 4(a)) and a recently increasing EA pattern in the second EOF (Figure 4(b)). The third and fourth EOFs have been identified as the SCAND (EU1) and EA/WR (EU2) patterns and hardly show any recent trend (not shown). This pattern identification is confirmed by high correlation coefficients between the NCEP/NCAR PC time series and seasonal means of the monthly NOAA-CPC (2010) teleconnection indices: 0.89 (NAO), 0.83 (EA), 0.64 (SCAND) and 0.70 (EA/WR).
The ECHAM5/MPI-OM winter circulation is characterized by the same four leading modes of variation but different temporal evolutions show only a slight NAO increase and an EA pattern decrease (Figure 4(a) and (b), right). Concerning the spatial configuration of the simulated modes of variation, the centre of action of the EA pattern lies further east over Great Britain and the SCAND pattern centre over Spain is more intensive compared to observations (not shown).

The leading EOFs of summer circulation are characterized by lower variability. In NCEP/NCAR, the first EOF shows wide-spread low pressure extending over whole Europe, Turkey and northern Africa and can be interpreted as some kind of blocking pattern with weakening intensity (Figure 4(c)). However, interpretation is difficult because there are also similarities to the subtropical zonal (SZ) pattern of Barnston and Livezey (1987) and the correlation coefficient to the NOAA-CPC (2010) NAO teleconnection index yields -0.40 . The second EOF describes a recently decreasing summer NAO pattern 


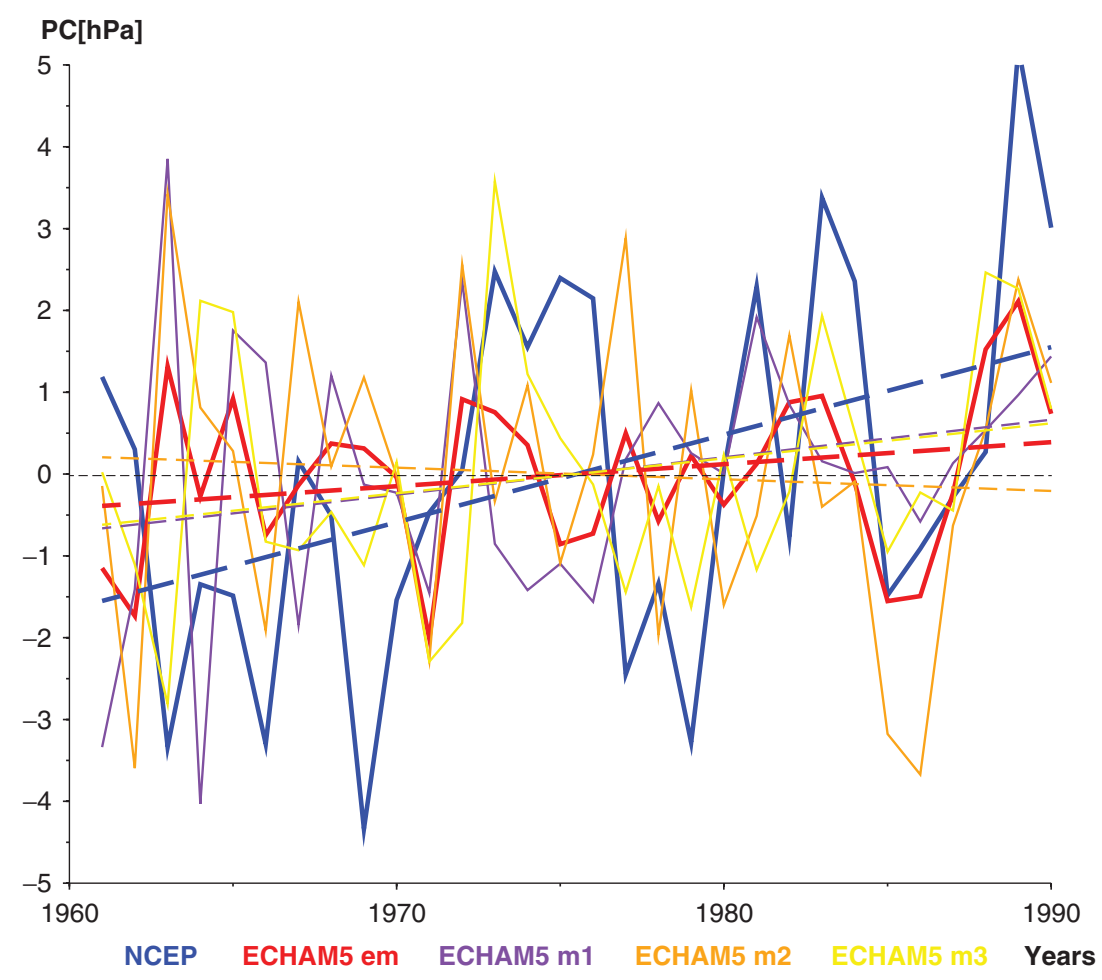

Figure 5. Comparison of PC time series of the first winter EOF during 1961-1990 (identified as NAO) and corresponding linear trend lines between the coupled GCM ECHAM5/MPI-OM ensemble mean (red), its ensemble members (purple, orange and yellow) and the reanalysis dataset NCEP/NCAR (blue).

(not shown) and the third EOF in Figure 4(d) a slightly increasing EA-Jet pattern (Dünkeloh and Jacobeit, 2003; NOAA-CPC, 2010). This can be confirmed by correlation coefficients of 0.76 and 0.62 to NOAA-CPC (2010) teleconnection indices. The first summer EOF of ECHAM5/MPI-OM resembles that of NCEP/NCAR but shows less variability of low pressures, especially over North Africa and Turkey, and slightly more variability of high pressures over Greenland. Thus, it is interpreted as slight blocking pattern as well. Furthermore, we can state the EA-Jet pattern in the second EOF centred further north-east over the Scandinavian Peninsula than in NCEP/NCAR and a slight summer version of the EA pattern in the third EOF (not shown). The NAO and SZ patterns with distinct centres over the northern Atlantic and North Africa, respectively, are hardly found in ECHAM5/MPI-OM. All simulated summer PC time series show only negligible recent trends (Figure 4(c) and (d), right).

Finally, in order to understand the differences between simulated and observed mid-latitude circulation variability the impact of initial conditions on circulation variability is estimated for three model simulations relying on different initial condition sets. Figure 5 shows for example the temporal evolution and variability of the first winter EOF (identified as NAO pattern) of the three ECHAM5/MPI-OM ensemble members. The different PC time series show high variability comparable to the observed NAO and strong differences to each other and to the ensemble mean in temporal evolution. The linear regression lines for 1961-1990 yield a great range of regression coefficients between +0.05 and -0.01 , but none of them reach the high regression coefficient of +0.11 of the observed NAO. Furthermore, the results of a one-way analysis of variance between the projected seasonal PC time series of the three ECHAM5/MPI-OM ensemble members during 1961-1990 show that the total variance accounted for by the residual component due to differing initial conditions exceeds $80 \%$ for each EOF in each season. Figure 6 depicts for example the results for EOF1 and EOF2 in winter and summer. The maximum explained variance due to an external $\mathrm{CO}_{2}$ forcing common to all ensemble members lies around $18 \%$ for EOF2 in winter and EOF10 in spring marginally reaching significance. A further investigation is performed to test if this strong impact of initial conditions on circulation dynamics decreases in future time periods with increasing atmospheric $\mathrm{CO}_{2}$ concentrations. Therefore, the one-way analysis of variance is applied to all 30-year time windows from 1961-1990 to 2021-2050. Figure 6 shows that in most cases (e.g. EOF1 in winter and summer) the treatment effect reveals strong variations with slight trends mostly not reaching significance. Only in some cases (e.g. EOF2 in summer) the fraction of external variability strongly increases reaching significance which indicates a possible future enhancement of predictability based on $\mathrm{CO}_{2}$. However, other cases even reveal intensive decreases of the treatment effect (e.g. EOF2 in winter). Thus, initial conditions have a strong present-day 

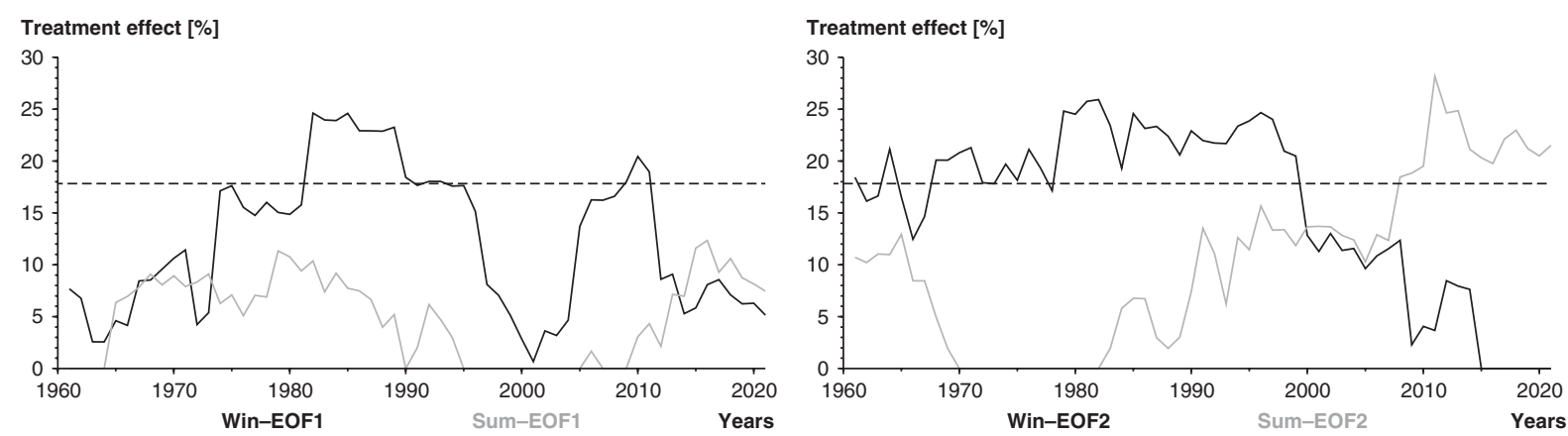

Figure 6. Results of one-way analysis of variance for the projected PC time series of three ECHAM5/MPI-OM ensemble members for all 30year time windows moving from 1961-1990 to 2021-2050 ( $x$-axis denotes first years of corresponding time windows, dashed line identifies significance level): fraction of external treatment effect [\%] for EOF1 (left) and EOF2 (right) in winter (black) and summer (grey).

impact on simulated circulation variability even remaining high in future time periods with increasing $\mathrm{CO}_{2}$ concentrations. One might conclude that 30 -year trends generally suffer from strong impacts of interdecadal variability, and thus only reveal low predictability based on $\mathrm{CO}_{2}$ because the considered timescale is shorter than that one affected by GHG forcing.

Thus, we find similar spatial patterns but strong differences in temporal evolutions comparing simulated and observed mid-latitude circulation variability in the Mediterranean area in winter and summer during 1961-1990. These differences are supposed to be induced by differing initial conditions in models and observations owing to strong impacts of initial conditions on simulated circulation variability.

\subsection{Multiple regression}

To determine the kind and strength of the impact of mid-latitude circulation variability on Mediterranean temperature and precipitation we perform a cross-validated stepwise multiple regression between regional E-OBS or REMO temperature and precipitation and large-scale NCEP/NCAR or ECHAM5/MPI-OM modes of variation during 1961-1990.

The multiple regression results for temperature yield homogeneous and strong correlations, especially in the western Mediterranean and during winter. Figure 7 (left) depicts for example the results for observed winter temperature. The maximum variance accounted for by all predictors of the statistical model reaches $70-80 \%$ over Spain and the Atlas Mountains and 30-50\% over the eastern Mediterranean (Figure 7, upper left). The first predictors are the EA pattern in the western Mediterranean and the NAO over Turkey (Figure 7, middle left). Over Bulgaria and northern Greece the EA/WR pattern shows most influence. These first predictors reach robustness values of over 0.9 in most regions (Figure 7, lower left). The results for models and the summer season are shortly discussed but not depicted: The simulated winter temperature shows similar results to observations but an overlapping influence of the EA pattern and the NAO over Turkey. In summer, most observed temperature variance $(60-70 \%)$ is explained by the fifth EOF of NCEP/NCAR (interpreted as a summer version of SCAND) over the Iberian Peninsula and we state further influences of the EA-Jet over Italy and the Atlas Mountains and of the blocking pattern over the Balkans and western Turkey. The simulated summer temperature shows correlations to the EA-Jet over southern Europe, to the slight blocking pattern over Galicia, Turkey and the Near East and to the summer EA pattern over northern Africa reaching a maximum explained variance of $50-60 \%$.

The multiple regression results for precipitation are more heterogeneous but still confirm the strong influence of large-scale circulation on the western Mediterranean in winter. As for temperature, the precipitation results are shown for example for observed winter data (Figure 7, right). Maximum variance explained by all predictors reaches up to $70-80 \%$ over western Turkey and the Iberian and Balkan peninsulas (Figure 7, upper right). The NAO is identified as the first predictor over southern Europe and some Turkish regions (Figure 7, middle right). However, there is some influence of the EA and SCAND patterns over Turkey as well. The robustness of these patterns mostly exceeds 0.9 (Figure 7, lower right). In eastern Turkey and the Near East we further find impacts of several less important modes of variation with robustness values reaching only $0.4-0.8$. The NAO is also identified as second predictor over whole western Turkey, likewise as the EA pattern over the Iberian Peninsula (not shown). Concerning simulated winter precipitation, the influence of the NAO is constrained to the Iberian Peninsula and the west coasts of Italy, the Balkans and Turkey and some impacts of the EA pattern over the Iberian Peninsula and of the SCAND pattern over southern Europe and north-western Africa can be identified. Maximum explained variance reaches $70-80 \%$ over the Iberian Peninsula. During summer, correlation between large-scale modes of variation and Mediterranean precipitation is generally much lower showing maximum explained variances of $30-50 \%$. Concerning observations, some influences of the EA-Jet pattern over Italy, the Balkans and Turkey occur. For simulated summer precipitation there are influences of the EA-Jet pattern over southern Europe as well and further impacts of the blocking pattern over Spain and Turkey. 

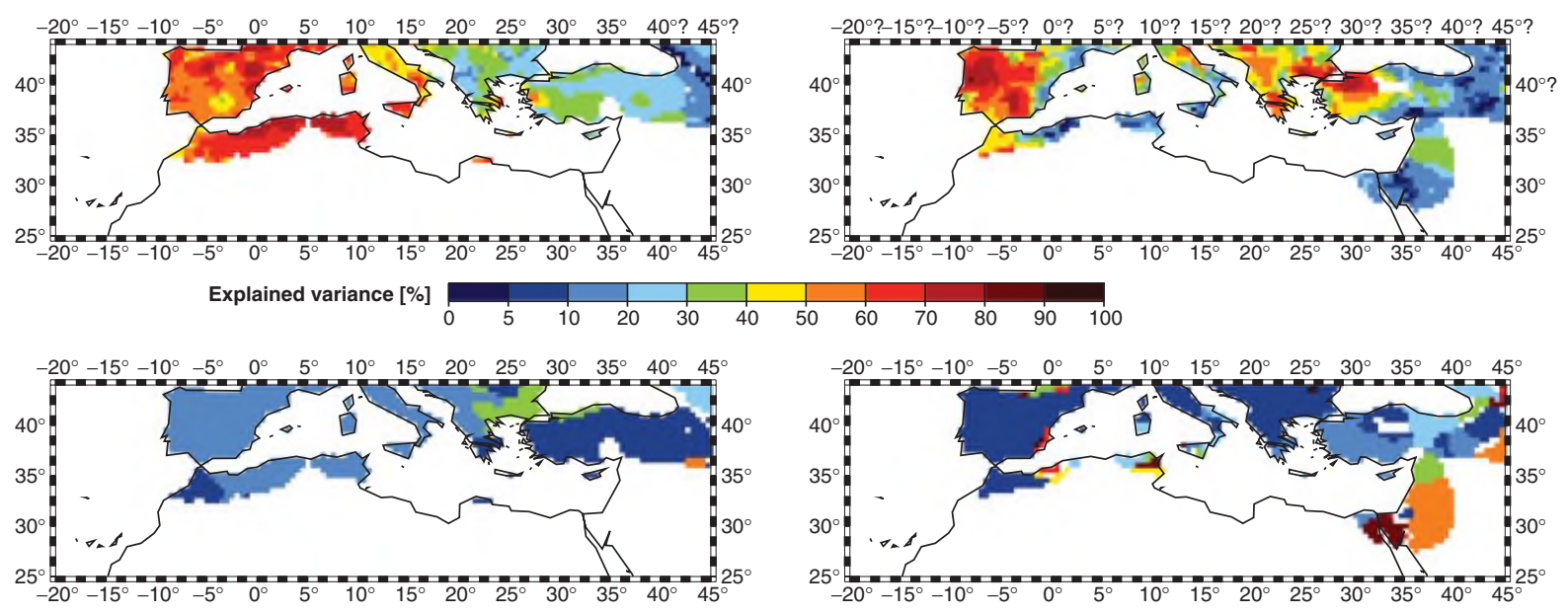

First predictor [EOF number]
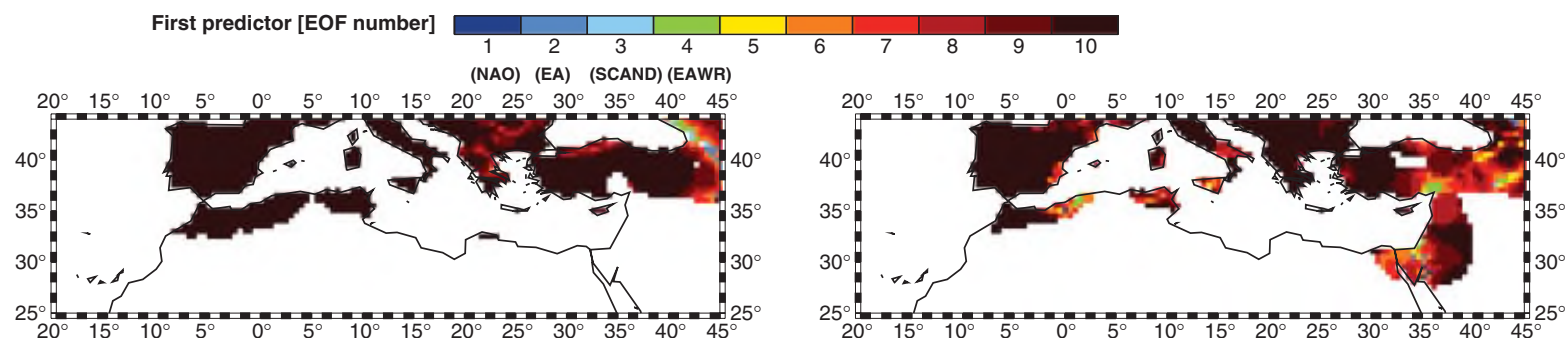

Robustness [share of total]

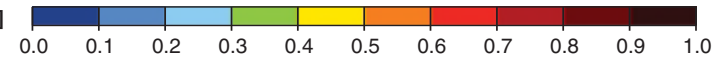

Figure 7. Results of cross-validated stepwise multiple regression based on E-OBS predictands and NCEP/NCAR predictors for winter temperature (left) and winter precipitation (right): temperature and precipitation variance explained by all circulation predictors selected by the statistical model (above), EOF number of first circulation predictor (middle) and its robustness over 1000 iterations (below).

We can conclude that mid-latitude circulation variability strongly impacts Mediterranean temperature and precipitation in both model and observations, especially over the western parts in winter. The presented multiple regression results strongly agree with former findings from the literature: strong impacts of the winter NAO on precipitation over the Iberian Peninsula (Ulbrich et al., 1999; Goodess and Jones, 2002; Trigo et al., 2004) and Turkey (Türkes and Erlat, 2005) as well as eastern Mediterranean temperature (Cullen and DeMenocal, 2000; Ben-Gai etal., 2001; Xoplaki, 2002) and further impacts of the winter EA pattern on western Mediterranean temperature (Sáenz et al., 2001). In summer, influencing patterns are found to be the EA-Jet (Dünkeloh and Jacobeit, 2003) and a blocking pattern resembling the SZ pattern (Barnston and Livezey, 1987).

\subsection{Circulation-unrelated seasonal trends}

The question arises whether the prevailing nesting approach forced by observed $\mathrm{CO}_{2}$ concentrations shows higher predictability for Mediterranean temperature and precipitation trends during 1961-1990 after removing the impact of mid-latitude circulation variability which strongly differs between model and observations. Thus, the circulation-related parts of temperature and precipitation variability, as determined by the stepwise multiple regression analysis, are removed from the original data and the remaining circulation-unrelated temperature and precipitation trends are analysed.
First, the seasonal trends of the circulation-unrelated parts of E-OBS and REMO winter temperature are discussed and compared with the original trends. The corresponding circulation-related trends are not depicted. The E-OBS circulation-unrelated part holds a not significant cooling trend over Turkey and only small trends over Spain (Figure 8, upper left). The strong original trends of E-OBS over Spain and Turkey (Figure 2, upper left) are mainly induced by an intense strengthening of the NAO and EA patterns, respectively. The corresponding circulation-unrelated part of REMO yields small but significant warming patterns over northern Italy, the Balkans and north-western Africa (Figure 8, upper right). The original trends of Figure 2 (upper right) can be explained by the impacts of both increasing NAO and decreasing EA patterns. Thus, the circulation-unrelated temperature trends of E-OBS and REMO match each other better than the original trends. However, there are still some differences in Turkey and some new ones prevailing over northern Italy. These minor discrepancies may be related to modes of variation neglected in the predictor setting, to differences in other factors of interdecadal model variability, e.g. oceanic forcing, or to other boundary conditions or mechanisms.

Concerning summer temperature, the circulationunrelated part of E-OBS shows no cooling trend over Turkey any more and a decrease of the western Mediterranean warming trends (Figure 8, lower left) in comparison to original data (Figure 2, lower left) 

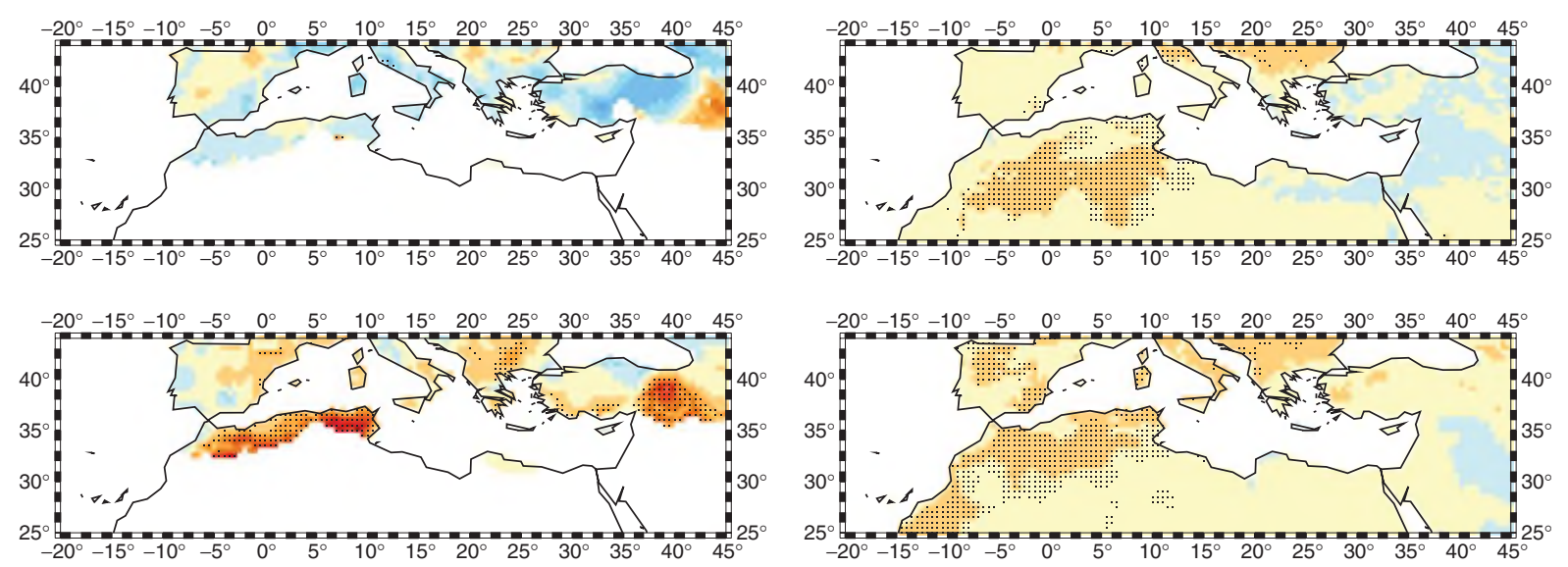

$\mathrm{T}\left[{ }^{\circ} \mathrm{C} / 30\right.$ years $]$

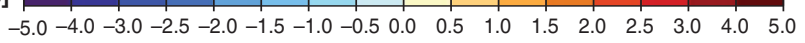

Figure 8. Comparison of circulation-unrelated winter (above) and summer (below) temperature trends during 1961-1990 between the regional climate model REMO (right) and the observational dataset E-OBS (left) after removal of influences by mid-latitude circulation variability applying a significance level of $5 \%$ (dots).

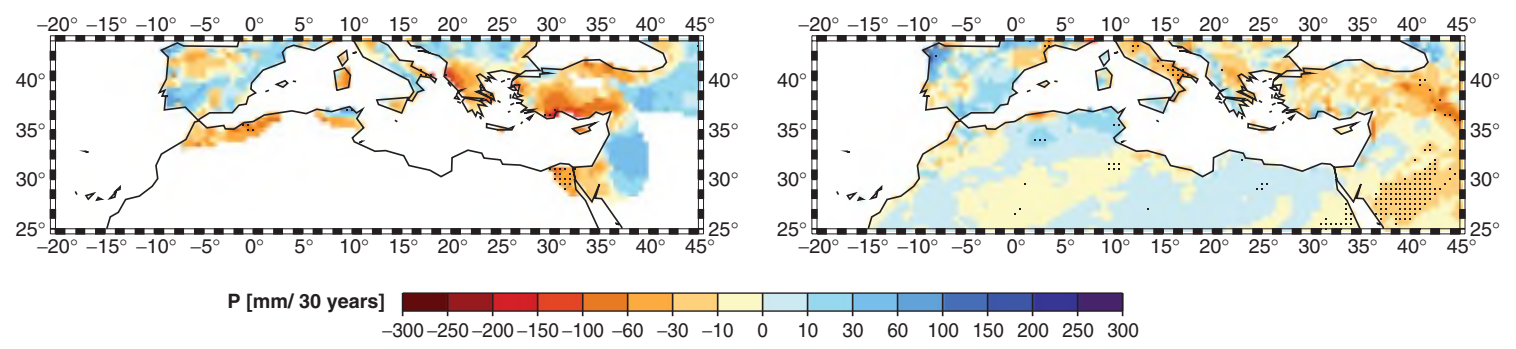

Figure 9. Same as Figure 8 but for winter precipitation.

after removing impacts of a decreasing blocking pattern over the Balkans and Turkey and an increasing EA-Jet pattern over the Atlas Mountains. The summer circulation-unrelated trends of REMO (Figure 8, lower right) closely resemble the original data trends (Figure 2, lower right) because hardly any impact of atmospheric circulation is detected. Thus, the agreement of summer temperature trends has strongly improved over the Atlas Mountains, the Balkans and western Turkey. Nevertheless, differences in intensity remain over Spain, the Atlas Mountains and eastern Turkey which can perhaps be explained by uncertainties and low density of high mountain station measurements. Different observational datasets differ over mountainous areas, e.g. the dataset from the Climatic Research Unit (CRU TS 2.1, Mitchell and Jones, 2005) does not show the strong E-OBS warming trend over eastern Turkey during 1961-1990.

Furthermore, we discuss the circulation-unrelated trends of winter precipitation in comparison to original trends. The circulation-unrelated part of E-OBS only yields some small and not significant drying patterns over Greece and Turkey and even wetting patterns over Galicia and Portugal (Figure 9, left). The strong trends of the original data (Figure 3, upper left) are particularly caused by drying impacts of a combined strong increase of the NAO and EA patterns. The circulation-unrelated part of REMO winter precipitation
(Figure 9, right) shows smaller drying trends than the original data (Figure 3, upper right), especially over the Iberian Peninsula even yielding wetter conditions over Galicia, after removal of influences of a strengthening NAO and a decreasing EA pattern. Agreement of winter precipitation trends can thus strongly be enhanced over southern Europe and Turkey by removing the impacts of mid-latitude circulation.

Concerning summer precipitation, the circulationunrelated parts of E-OBS and REMO show nearly no significant trends and look quite similar to the original data trends (Figure 3, lower left and right) and are therefore not depicted here. Besides small impacts of an increasing EA-Jet pattern in observations hardly any impacts of circulation are found. Consequently, removing circulation-related parts of variability shows nearly no influence on summer precipitation trends.

Thus, in most Mediterranean regions the predictability of this nesting approach increases after removing the impact of mid-latitude circulation variability. Areas with high agreement of circulation-unrelated trends indicate where the predictability for seasonal temperature and precipitation based on observed $\mathrm{CO}_{2}$ concentrations reaches sufficiency if the impact of mid-latitude circulation variability is disregarded. Areas with strong disagreement between circulation-unrelated trends identify 

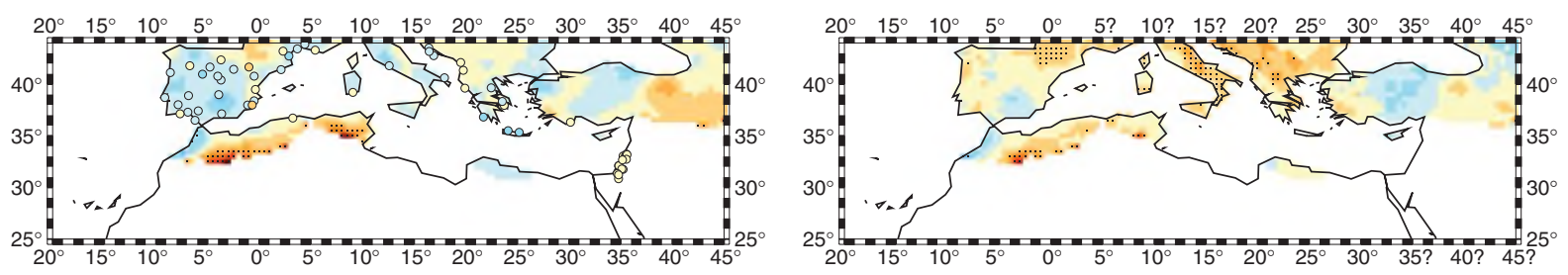

$\mathrm{T}\left[{ }^{\circ} \mathrm{C} / 30\right.$ years $]$

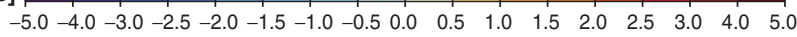

Figure 10. Comparison between original spring temperature trends during 1961-1990 of the observational dataset E-OBS (left) and original station data (left, circles) and corresponding circulation-unrelated trends of E-OBS after removal of influences by mid-latitude circulation variability (right) applying a significance level of 5\% (dots, bold circles).

Mediterranean regions where temperature and precipitation variability is influenced as well by further factors, e.g. tropical climate dynamics or ocean-atmosphere interactions. Thus, the predictability based on observed $\mathrm{CO}_{2}$ concentrations remains low. Note that the impacts of GHG forcing on circulation variability should not be neglected in this discussion but the one-way analysis of variance for ECHAM5/MPI-OM modes of variation (see above) reveals that they are rather small $(<20 \%$ of explained variance) during 1961-1990 compared with the impacts of initial conditions ( $>80 \%)$.

\subsection{Spring and autumn results}

During spring and autumn, the impact of mid-latitude circulation variability on Mediterranean temperature and precipitation is generally smaller than in winter but larger than in summer concerning the maximum explained variances in multiple regression analysis. The agreement of temperature and precipitation trends between model and observations, and thus the predictability of this nesting approach can be enhanced as well by removing the influences of mid-latitude circulation variability (not shown) except for spring temperature. The circulationunrelated spring temperature trends of simulations and observations do not fit as well as the small and mostly not significant original data trends. This is due to a cooling influence of an increasing SCAND pattern in southern Europe in E-OBS whose removal leads to a significant warming pattern in the circulation-unrelated part that is not reproduced in REMO. This example is depicted in Figure 10 and shows that a significant temperature or precipitation trend in the circulationrelated part can counterbalance a significant equal-sized trend of opposite sign in the circulation-unrelated part (Figure 10, right) so that the original data does not reveal any significant trend at all (Figure 10, left). This proves that removing the impact of mid-latitude circulation variability, i.e. the circulation-related part, from the original temperature or precipitation trends does not necessarily reduce the signal-to-noise-ratio. However, it can also reveal significant trends in the circulationunrelated part that have been masked before by opposite trends forced by large-scale circulation.

\section{Summary and conclusions}

In this study, we investigate if REMO driven by ECHAM5/MPI-OM and observed $\mathrm{CO}_{2}$ concentrations shows predictability for Mediterranean temperature and precipitation trends during 1961-1990. This region is especially suited for this analysis because it is identified as climate change hot spot being highly responsive to future climate change but strongly influenced by the interdecadal variability of mid-latitude circulation. We find that this nesting approach is not able to reproduce the observed strong trends, especially in winter. Thus, the model predictability based on observed $\mathrm{CO}_{2}$ concentrations in this hot spot region is low highlighting that radiative forcing is not the only driver of Mediterranean temperature and precipitation variability during 1961-1990.

Concerning impacts of mid-latitude circulation, we can state similar spatial patterns but differing temporal evolutions of simulated and observed circulation variability probably induced by different initial conditions. For 30-year periods, the one-way analysis of variance for ECHAM5/MPI-OM ensemble members shows strong impacts of initial conditions on circulation variability (mostly $>75-80 \%$ of explained variance) in present-day as well as future times with increasing GHG concentrations (compared with rather small impacts of GHG forcing: mostly $<20-25 \%$ ). For example, differing winter NAO trends of ECHAM5/MPI-OM members relate to strongly differing temperature and precipitation trends of corresponding REMO members. Furthermore, a cross-validated stepwise multiple regression reveals and quantifies the strong impacts of mid-latitude circulation on Mediterranean temperature and precipitation, especially on winter temperature over the western parts (60-80\% of explained variance), winter precipitation over the Iberian Peninsula and western Turkey $(70-80 \%)$ and summer temperature over the Iberian Peninsula and Libya (50-70\%). Summer precipitation shows only minor impacts of circulation (maximum $30-50 \%$ over Italy and the Balkans). Thus, some explanations for differing observed and simulated climate trends are found: In winter, the stronger observed NAO increase induces a larger cooling over Turkey and a larger drying over 
southern Europe and Turkey. Opposite temporal evolutions of the observed and simulated EA pattern cause opposite temperature trends in southern Europe. In summer, the stronger decrease of the observed blocking pattern induces a larger cooling over the Balkans and western Turkey, and a more increasing EA-Jet causes a larger warming over the Atlas Mountains.

The second main question is if REMO driven by ECHAM5/MPI-OM and observed $\mathrm{CO}_{2}$ concentrations shows higher predictability for Mediterranean temperature and precipitation trends in 1961-1990 after removing the impact of mid-latitude circulation variability which seems to be unpredictable owing to its strong dependence on initial conditions. In most Mediterranean areas, the circulation-unrelated temperature or precipitation trends of REMO and E-OBS reveal a somewhat stronger agreement than original trends. Therefore, the model predictability increases by removing the impact of mid-latitude circulation. Areas with high agreement between simulated and observed circulation-unrelated trends might indicate regions with similar change in the background state of regional climate due to increasing GHG concentrations, e.g. the significant summer warming over the western and central parts and the small winter drying over the eastern parts. Areas with strong disagreement of circulation-unrelated trends, e.g. eastern Turkey, might identify regions where temperature and precipitation variations are influenced by factors of interdecadal variability not considered in the statistical model, e.g. tropical climate dynamics like El Niño-Southern Oscillation (ENSO) and Asian or African monsoons (Price etal., 1998; Ziv etal., 2004; Mariotti etal., 2005; PozoVázquez etal., 2005; Seubert, 2010). Further explanations might point to deficiencies in model performance or station data, e.g. low station density over mountains. For instance, the CRU TS 2.1 dataset (Mitchell and Jones, 2005) reveals results which differ from E-OBS, e.g. less intensity in summer warming over eastern Turkey and the Atlas Mountains, winter cooling over Turkey and winter drying over the whole area in original and circulationunrelated trends (not shown).

Several conclusions can be drawn from the results of this study: We find large impacts of initial conditions on the interdecadal variability of mid-latitude circulation which strongly influences not only annual values but also 30-year RCM trends during 1961-1990. Increasing GHG concentrations only play a minor role at that timescale. Therefore, we can conclude that low predictability of a nesting approach based on observed $\mathrm{CO}_{2}$ concentrations is not necessarily an indication of deficient model performance in projecting GHG-related climate change. Instead, it can also arise from unknown initial conditions and interdecadal model variability which differ from the observed climate and mask background climate change trends. In general, the problem of unknown initial conditions of a climate model simulation cannot be solved, always resulting in out-of-phase relationships between models and observations at timescales beyond climate predictability from a given forcing (like in this study).
However, we present an approach to quantify the relative importance of the predictable external GHG forcing versus the unpredictable internal variability, e.g. initial conditions and mid-latitude circulation, for Mediterranean temperature and precipitation trends which can be easily transferred to other regions or factors of interdecadal variability. Finally, increased predictability of a climate model approach based on radiative forcing may be found at timescales longer than 30 years which are closer to its predictive timescale ( $c f$ Paeth and Hense, 2002). Another option to reach higher model predictability at shorter timescales is to consider further real boundary conditions in climate models besides GHG emissions, e.g. aerosol effects (Paeth and Feichter, 2006, Zubler etal., 2011) or anthropogenic land cover changes (Paeth et al., 2009) - a challenge for future investigations in the context of decadal climate forecast attempts.

\section{Acknowledgements}

This work has been carried out within the research project KLIWEX-MED (Climate Change and Extreme Events in the Mediterranean Area) funded by the German Research Foundation (DFG). We acknowledge the E-OBS dataset from the EU-FP6 project ENSEMBLES (http://www.ensembles-eu.org/), the data set from the ECA\&D project (http://eca.knmi.nl) and the NCEP/NCAR Reanalyses provided by the NOAA/OAR/ESRL PSD, Boulder, Colorado, USA, from their web site at http://www.esrl.noaa.gov/psd/. Furthermore, we thank Sebastian Mutz for editing the language of the manuscript.

\section{References}

Barnston A, Livezey RE. 1987. Classification, seasonality and persistence of low-frequency atmospheric circulation patterns. Mon. Weather Rev. 115: 1083-1126.

Ben-Gai T, Bitan A, Manes A, Alpert P, Kushnir Y. 2001. Temperature and surface pressure anomalies in Israel and the North Atlantic Oscillation. Theor. Appl. Climatol. 69: 171-177.

Christensen JH, Hewitson B, Busuioc A, Chen A, Gao X, Held I, Jones R, Kolli RK, Kwon W-T, Laprise R, Magaña Rueda V, Mearns L, Menéndez CG, Räisänen J, Rinke A, Sarr A, Whetton P. 2007. Regional climate projections. In Climate Change 2007: The Physical Science Basis. Contribution of Working Group I to the Fourth Assessment Report of the Intergovernmental Panel on Climate Change, Solomon S, Qin D, Manning M, Chen Z, Marquis M, Averyt KB, Tignor M, Miller HL (eds). Cambridge University Press: Cambridge, UK and New York, NY; 847-940.

Conte M, Giuffrida A, Tedesco S. 1989. The Mediterranean oscillation: impact on precipitation and hydrology in Italy. Proceedings of the Conference on Climate and Water, Vol. 1, Publications of the Academy of Finland: Helsinki, 121-137.

Cullen HM, deMenocal PB. 2000. North Atlantic influence on Tigris-Euphrates streamflow. Int. J. Climatol. 20: 853-863.

Déqué M, Jones RG, Wild M, Giorgi F, Christensen JH, Hassell DC, Vidale PL, Rockel B, Jacob D, Kjellstrom E, de Castro M, Kucharski F, van den Hurk B. 2005. Global high resolution versus Limited Area Model climate change projections over Europe: quantifying confidence level from PRUDENCE results. Clim. Dyn. 25: 653-670.

Deser C, Knutti R, Solomon S, Phillips AS. 2012. Communication of the role of natural variability in future North American climate. Nat. Clim. Change 2: 775-779.

Dünkeloh A, Jacobeit J. 2003. Circulation dynamics of Mediterranean precipitation variability 1948-98. Int. J. Climatol. 23: 1843-1866. 
Gibson R, Kallberg P, Uppala S, Hernandez A, Nomura A, Serrano E. 1997. ERA description. Re-Analysis Project Report Series No. 1. European Centre for Medium-Range Weather Forecasts (ECMWF). Reading, UK.

Giorgi F. 2006. Climate change hot-spots. Geophys. Res. Lett. 33: L08707, DOI: 10.1029/2006GL025734.

Giorgi F, Lionello P. 2008. Climate change projections for the Mediterranean region. Global Planet. Change 63: 90-104.

Giorgi F, Bi X, Pal JS. 2004. Means, interannual variability and trends in a regional climate change experiment over Europe. I. Present day climate (1961-1990). Clim. Dyn. 22: 733-756.

Goodess CM, Jones PD. 2002. Links between circulation and changes in the characteristics of Iberian rainfall. Int. J. Climatol. 22: $1593-1615$.

Haylock MR, Hofstra N, Klein Tank AMG, Klok EJ, Jones PD, New M. 2008. A European daily high-resolution gridded dataset of surface temperature and precipitation for 1950-2006. J. Geophys. Res. 113: D20119, DOI: 10.1029/2008JD10201.

Hurrell JW. 1995. Decadal trends in the North Atlantic Oscillation: regional temperatures and precipitation. Science 269: 676-679.

Jacob D, Van den Hurk BJJM, Andrae U, Elgered G, Fortelius C, Graham LP, Jackson SD, Karstens U, Köpken C, Lindau R, Podzun R, Rockel B, Rubel F, Sass BH, Smith RNB, Yang X. 2001. A comprehensive model inter-comparison study investigating the water budget during the BALTEX-PIDCAP period. Meteorol. Atmos. Phys. 77: $19-43$.

Jacob D, Bärring L, Christensen OB, Christensen JH, de Castro M, Déqué M, Giorgi F, Hagemann S, Hirschi M, Jones R, Kjellström E, Lenderink G, Rockel B, Schär C, Seneviratne SI, Somot S, van Ulden A, van den Hurk B. 2007. An inter-comparison of regional climate models for Europe: model performance in present day climate. Clim. Change 81: 31-52, DOI: $10.1007 / \mathrm{s} 10584-006-9213-4$.

Jacobeit J, Dünkeloh A, Hertig E. 2007. Mediterranean Rainfall Changes and their Causes. In Global Change: Enough Water for All?, Lozán J, Graßl H, Hupfer P, Menzel L, Schönwiese CD (eds). Wissenschaftliche Auswertungen: Hamburg, Germany; 195-199.

Kalnay E, Kanamitsu M, Kistler R, Collins W, Deaven D, Gandin LS, Iredell M, Saha S, White G, Woolen J, Zhu Y, Chelliah M, Ebisuzaki W, Higgins W, Janowiak J, Mo KC, Ropelewsky C, Wang J, Leetma A, Reynolds R, Jenne R, Joseph D. 1996. The NCEP/NCAR 40-year Reanalysis Project. Bull. Am. Meteorol. Soc. 77: 437-471.

Klein Tank AMG, Wijngaard JB, Können GP, Böhm R, Demarée G, Gocheva A, Mileta M, Pashiardis S, Hejkrlik L, Kern-Hansen C, Heino R, Bessemoulin P, Müller-Westermeier G, Tzanakou M, Szalai S, Pálsdóttir T, Fitzgerard D, Rubin S, Capaldo M, Maugeri M, Leitass A, Bukantis A, Aberfeld R, Van Engelen AFV, Forland E, Mietus M, Coelho F, Mares C, Razuvaev V, Nieplova E, Cegnar T, Antonio López J, Dahlström B, Moberg A, Kirchhofer W, Ceylan A, Pachaliuk O, Alexander LV, Petrovic P. 2002. Daily dataset of the 20th-century surface air temperature and precipitation series for the European climate assessment. Int. J. Climatol. 22: $1441-1453$.

Krichak SO, Alpert P. 2005. Decadal trends in the east Atlantic-west Russia pattern and Mediterranean precipitation. Int. J. Climatol. 25: 183-192.

Kunstmann H, Heckl A, Rimmer A. 2006. Physically based distributed hydrological modelling of the Upper Jordan catchment and investigation of effective model equations. Adv. Geosci. 9: 123-130.

Mariotti A, Ballabrera-Poy J, Zeng N. 2005. Tropical influence on Euro-Asian autumn rainfall variability. Clim. Dyn. 24: 511-521.

Mitchell TD, Jones PD. 2005. An improved method of constructing a database of monthly climate observations and associated highresolution grids. Int. J. Climatol. 25: 693-712.

Moberg A, Jones PD. 2005. Trends in indices for extremes in daily temperature and precipitation in central and western Europe 1901-1999. Int. J. Climatol. 25: 1149-1171.

Moberg A, Jones PD, Lister D, Walther A, Brunet M, Jacobeit J, Alexander LV, Della-Marta P, Luterbacher J, Yiou P, Chen D, Klein Tank A, Saladié O, Sigró J, Aguilar E, Alexandersson H, Almarza C, Auer I, Barriendos M, Begert M, Bergström H, Böhm R, Butler CJ, Caesar J, Drebs A, Founda D, Gerstengarbe FW, Micela G, Maugeri M, Österle H, Pandzic K, Petrakis M, Srnec L, Tolasz $\mathrm{R}$, Tuomenvirta H, Werner PC, Linderholm H, Philipp A, Wanner H, Xoplaki E. 2006. Indices for daily temperature and precipitation extremes in Europe analysed for the period 1901-2000. J. Geophys. Res. 111: D22106, DOI: 10.1029/2006JD007103.

Nakicenovic N, Swart R. 2000. Emissions Scenarios. Cambridge University Press: Cambridge, UK.
New M, Hulme M, Jones P. 2000. Representing twentieth century space-time climate variability. Part II: Development of 1901-96 monthly grids of terrestrial surface climate. J. Clim. Appl. Meteorol. 13: $2217-2238$

NOAA-CPC. 2010. Northern Hemisphere Teleconnection Patterns. NOAA National Weather Service Climate Prediction Center. http://www.cpc.noaa.gov/data/teledoc/telecontents.shtml.

Osborn TJ. 2004. Simulating the winter North Atlantic Oscillation: the roles of internal variability and greenhouse gas forcing. Clim. Dyn. 22: 605-623.

Paeth H, Feichter J. 2006. Greenhouse-gas versus aerosol forcing and African climate response. Clim. Dyn. 26: 35-54.

Paeth H, Hense A. 2002. Sensitivity of climate change signals deduced from multi-model Monte Carlo experiments. Clim. Res. 22: 189-204.

Paeth H, Hense A. 2003. Seasonal forecast of sub-Sahelian rainfall using cross validated model output statistics. Meteorol. Zeit. 12: $157-173$.

Paeth H, Hense A. 2005. Mean versus extreme climate in the Mediterranean region and its sensitivity to future global warming conditions. Meteorol. Zeit. 14: 329-347.

Paeth H, Born K, Podzun R, Jacob D. 2005. Regional dynamical downscaling over West Africa: model evaluation and comparison of wet and dry years. Meteorol. Zeit. 14: 349-367.

Paeth H, Girmes R, Menz G, Hense A. 2006. Improving seasonal forecasting in the low latitudes. Mon. Weather Rev. 134: 1859-1879.

Paeth H, Born K, Girmes R, Podzun R, Jacob D. 2009. Regional climate change in tropical and northern Africa due to greenhouse forcing and land use changes. J. Climate 22: 114-132.

Pozo-Vázquez D, Gámiz-Fortis SR, Tovar-Pescador J, Esteban-Parra MJ, Castro-Díez Y. 2005. El Niño-Southern Oscillation events and associated European winter precipitation anomalies. Int. J. Climatol. 25: $17-31$

Price C, Stone L, Huppert A, Rajagopalan B, Alpert P. 1998. A possible link between El Niño and precipitation in Israel. Geophys. Res. Lett. 25: 3963-3966.

Quadrelli R, Pavan V, Molteni F. 2001. Wintertime variability of Mediterranean precipitation and its links with large-scale circulation anomalies. Clim. Dyn. 17: 457-466.

Rauthe M, Hense A, Paeth H. 2004. A model intercomparison study of climate change signals in extratropical circulation. Int. J. Climatol. 24: 643-662.

Roeckner E, Arpe K, Bengtsson L, Christoph M, Claussen M, Dumenil L, Esch M, Giorgetta M, Schlese U, Schulzweida U. 1996. The atmospheric general circulation model ECHAM-4: Model description and simulation of present-day climate. Max-PlanckInstitute for Meteorology Report 218, Hamburg, Germany.

Roeckner E, Baeuml G, Bonaventura L, Brokopf R, Esch M, Giorgetta M, Hagemann S, Kirchner I, Kornblueh L, Manzini E, Rhodin A, Schlese U, Schulzweida U, Tompkins A. 2003. The atmospheric general circulation model ECHAM5. Part I: Model description. MaxPlanck-Institute for Meteorology Report 349, Hamburg, Germany

Sáenz J, Rodríguez-Puebla C, Fernández J, Zubillaga J. 2001. Interpretation of interannual winter temperature variations over southwestern Europe. J. Geophys. Res. 106: 20641-20651.

Seubert S. 2010. Telekonnektionen des Niederschlags im Mittelmeerraum zur Zirkulation in den Tropen. Dissertation, University of Augsburg, Germany. http://opus.bibliothek.uniaugsburg.de/volltexte/2010/1646/.

Trigo IF, Davies TD, Bigg GR. 2000. Decline in Mediterranean rainfall caused by weakening of Mediterranean cyclones. Geophys. Res. Lett. 27: 2913-2916.

Trigo RM, Pozo-Vazquez D, Osborn TJ, Castro-Diez Y, Gamiz-Fortis S, Esteban-Parra MJ. 2004. North Atlantic Oscillation influence on precipitation, river flow and water resources in the Iberian Peninsula. Int. J. Climatol. 24: 925-944.

Trigo R, Xoplaki E, Zorita E, Luterbacher J, Krichak SO, Alpert P, Jacobeit J, Sáenz J, Fernández J, González-Rouco F, Garcia-Herrera R, Rodo X, Brunetti M, Nanni T, Maugeri M, Türkeş M, Gimeno L, Ribera P, Brunet M, Trigo IF, Crepon M, Mariotti A. 2006. Relations between variability in the Mediterranean region and midlatitude variability. In Mediterranean Climate Variability, Lionello P, Malanotte-Rizzoli P, Boscolo R (eds). Elsevier: Amsterdam, The Netherlands; $179-226$.

Türkes M, Erlat E. 2005. Climatological responses of winter precipitation in Turkey to variability of the North Atlantic Oscillation during the period 1930-2001. Theor. Appl. Climatol. 81: 45-69. 
Ulbrich U, Christoph M, Pinto JG, Corte-Real J. 1999. Dependence of winter precipitation over Portugal on NAO and baroclinic wave activity. Int. J. Climatol. 19: 379-390.

Von Storch H, Zwiers FW. 1999. Statistical Analysis in Climate Research. Cambridge University Press: Cambridge, UK.

Wang G. 2005. Agricultural drought in a future climate: results from 15 global climate models participating in the IPCC 4th assessment. Clim. Dyn. 25: 739-753.

Wijngaard JB, Klein Tank AMG, Können GP. 2003. Homogeneity of 20th century European daily temperature and precipitation series. Int. J. Climatol. 23: 679-692.

Wilks DS. 2006. Statistical Methods in the Atmospheric Sciences, 2nd edn. Amsterdam, The Netherlands: Elsevier Academic Press.
Xoplaki E. 2002. Climate Variability over the Mediterranean. Dissertation, University of Bern, Switzerland. http://sinus.unibe.ch/klimet/ docs/phd_xoplaki.pdf.

Xoplaki E, Gonzalez-Rouco JF, Luterbacher J, Wanner H. 2004. Wet season Mediterranean precipitation variability: influence of largescale dynamics and trends. Clim. Dyn. 23: 63-78.

Ziv B, Saaroni H, Alpert P. 2004. The factors governing the summer regime of the eastern Mediterranean. Int. J. Climatol. 24: $1859-1871$.

Zubler EM, Folini D, Lohmann U, Luthi D, Muhlbauer A, PousseNottelmann S, Schaer C, Wild M. 2011. Implementation and evaluation of aerosol and cloud microphysics in a regional climate model. J. Geophys. Res. 116: D02211, DOI: 10.1029/2010JD014572. 